\title{
CRISES AND SYSTEMS THINKING
}

\author{
Author(s) / Auteur(s) : \\ Janos KORN \\ Dr, Independent Scientist \\ janos999@btinternet.com
}

\begin{abstract}
Résumé :
Tragedy, disaster or disorder precedes a situation labelled 'crisis', if it occurs. Tragedy, disaster or disorder is potentially present in all scenarios which function according to expectations or normally, they are dormant in any part of the world. A structural or linguistic model of a scenario reveals its constituents i.e. objects or agents, their properties and qualified interactions as seen by an investigator. Thus, objects and interactions are open to unravelling those features which are considered prone to tragedy or vulnerable to disasters or possibly incurring disorder, each to a varying degree. Therefore, new structures can be foreseen, planned, designed and introduced into a scenario to reduce chances of disasters occurring and possibly followed by crisis situations. A linguistic, operational model also allows the analysis and simulation of scenarios when real or imaginary crisis has occurred and crisis management has been introduced with effectiveness measured by 'certainty factors', for example. Currently workers in the field of crisis appear to concentrate on its nature and management and express their ideas in a descriptive manner. In this paper this is supplemented by showing how background scenarios can be operationally modelled in which potential tragedies, disasters or disorders are embedded. Crisis management is seen as a kind of problem solving and as such is amenable to being engineered by the method introduced here.
\end{abstract}

Keywords / Mots-clés :

crisis, systems thinking, linguistic modeling, uncertainties

\section{INTRODUCTION}

The term 'crisis' refers to an event considered as 'time of aggravated and intense difficulty or danger (possibly life threatening, confusing or damaging to the image, reputation of an organisation etc) [added by author]' [Anon., 1994] which is related to terms like: 'Tragedy' as far as living things in particular humans and 'disaster or disorder' as far as living and inanimate things, are concerned. Either of these precedes the event perceived and then designated as 'crisis'. The two types of terms are related : A tragedy or disaster occurs in the context of a 'normal but potentially problematic scenario' and can bring about a crisis situation. The relation is causal and necessary when they do happen i.e. without tragedy or disaster no crisis can occur but this is not mandatory because the term 'crisis' when an event is labelled as such needs to be arrived at by inspection of the characteristics of a scenario and subsequently interpreted by human observers and be judged as such. Accordingly, a crisis situation can have the following form of scenarios as described under the points :

I. A problematic scenario which is available for inspection either physically or as a hypothetical plan, a scheme, a story or a model prepared by 'linguistic modelling' [Korn, 2009, 2018] and contains the sources of potential tragedy or disaster and the potential causal agents which can trigger crisis as far as can be deduced from a model subject to interpretation.

As a result of preventive or proactive activities the chances of tragedy or disaster can be lessened or averted all together so that crisis does not occur. Activities to this effect can be carried out because the objects or agents, their characteristics and qualified interactions of a model of the problematic scenario in question are available so their features considered prone to tragedy or vulnerable to disaster or 
disorder, can be assessed. Accordingly, action can be taken to avoid tragedy or disaster which can lead to non - occurrence of crisis. Action is implemented by new structures operating in a purposive, dynamic manner [Nise, 2008, Korn, 2018].

II. The scenario with the tragedy or disaster having occurred as a result of action by causal agents and has led to a situation which can be interpreted as crisis and possibly showing the remedial, purposive action or 'crisis management' towards alleviating the effects of the crisis.

Currently the term 'crisis' is defined according to its causes as 'natural' [earthquake], 'technological' [industrial accident, product recalls], 'societal' [kidnapping, war, poisoning of food or water supplies] and 'managerial' [charges of wrongdoing by officers of an organisation] which occur outside or inside of an organisation or to individuals. Consideration of systemic ideas like complexity and variety is given unrelated to crisis theory [Gilpin, Murphy, 2008]. A historical review of works regarding 'crisis management' is described [Khodarahmi, 2009] which shows strong concentration of thoughts on 'crisis management' by defining 'crisis variables' as the vehicles for communication perhaps related to point II. Theoretical approaches to 'crisis situations' countering mainly damages to image or reputation of an organisation based on understanding a situation so as to select an appropriate crisis communication strategy [Coombs, 1998, Wang, et al., 2018]. The need for a proactive approach to crises rather than just reactive is outlined in [Jaques, 2010], a topic which is related to points $\mathbf{I}$. It is difficult to see how these approaches to crisis situations and management can handle cases at operational level since they do not appear to suggest the appropriate models.

The problematic issue appears to be that currently researchers are mainly occupied with consideration of crisis management which is of immediate concern, thus, paying less attention to aspects of scenarios from which crises originate. The approach of security companies appears to be characterised by less theoretical depth due to their interest in simulation of and exercises in crisis situations using software as can be seen from a brief survey of the Internet. Accordingly, the intention of this paper is :

To attempt to give a more general background to the concept of crisis,

To show how to use 'linguistic modelling' to model scenarios at operational level from which features of objects and interactions can be deduced to lead to the corresponding crisis preventive means realised by the introduction of new structures into a scenario, and

To demonstrate how to deal with situations when crisis has already seen to have occurred.

\section{DESCRIPTION OF SYSTEMS THINKING}

Practically all products of human intellectual endeavour have been created by means of the symbolisms of :

Natural language to express the large variety of thoughts such as kinds of literature, laws, philosophy, scientific writings, ideas of mysticism and superstition and so on,

Variety of signs and signals,

Fine and performing arts including films, and

Mathematical models of conventional science of physics.

The underlying thought of 'selecting a part of the world and expressing a belief about it' in all these branches of intellectual endeavour is carried by the 'subject - predicate' form. In natural language which is the primary symbolism for creating models and is immediately comprehensible, this form is realised by declarative sentences using 'qualitative and/or quantitative' properties of things (concrete, abstract, symbolic) in predicating the subject. It is only lately that significant interest has been paid to the use of 'structural' properties of things in the predicate which has led to the studies of 'scenarios' or 
'related or interacting objects in static or dynamic state' respectively. When we think in terms of sentences with 'structural properties' we are engaged in 'systems thinking' [Nise, 2008, Korn, 2009, 2012, 2013, 2015, 2016, 2018].

The change in paradigm or in viewing parts of the world calls for a new approach consisting of 'three empirical principles' which are applied to scenarios by the symbolism of linguistic structures or linguistic modelling [Kuhn, 1996, Korn, 2018]. In practice, linguistic modelling of scenarios is used as follows :

1. A selected part of the world is described by a 'story' or 'narrative' in natural language,

2. The story is converted by linguistic analysis of linguistic complexities into homogeneous language consisting of 1 - and 2 - place sentences which are the 'first level of abstractions' towards constructing an operational model [Korn, Huss, Cumbers, 1991, Korn, 2009]. The verb in a 1 - place sentence attracts one noun phrase such as in 'The boy (feeling hot) jumped (into the swimming pool)'. The verb in a 2 - place sentence attracts two noun phrases, for example, 'The (hospitable) boy (cordially) invited his friend (to lunch)'. The expressions in brackets are adjectival and adverbial qualifiers of noun phrases and verbs referred to as 'linguistic variables'[Burton, 1984]. These variables make the attributes, believes, characteristics, intentions or states of individuals more specific and enable them to generate 'relations' or 'interactions' [Korn, 2016]. 1 - and 2 - place sentences are the elementary constituents of which the story of a scenario (static or dynamic) can be reconstructed in a structured way.

3. The semantic content of elements of 1 - and 2 - place sentences are to be associated with terms used in describing structure. For example, 'relations' are designated by 'stative verbs', 'interactions' are designated by 'dynamic verbs' which constitute the 'second level of abstractions' [Korn, 2016].

4. This step consists of viewing 1 - and 2 - place sentences with 'stative verbs' as 'Ordered pairs' in static state leading to the construction of

'Linguistic networks' of 'products'

1 - and 2 - place sentences with dynamic verbs are expressed as 'Predicate logic statements' leading to the construction of

'Semantic diagrams' [Korn, 2009] which are the 'third level of abstraction'.

A semantic diagram shows the algorithm or topology or syntax of a scenario with explicit availability of the semantic or empirical content (concrete or abstract) of each object or agent and interaction.

The objective of constructing a linguistic model is to explicitly exhibit the role or function of theoretical objects in a scenario, initiating and affected, the interactions and the qualifiers of both to create a structure with an outcome which emerges from the aggregation in accordance with the $2^{\text {nd }}$ principle of systems [Korn, 2018]. The model allows the linguistic variables to vary so that this effect for each set of variations can be explored as far as the ability of outcome through a 'product' to resolve a problematic issue is concerned. In turn, resolution, if possible and acceptable, influences further behaviour of a 'User/consumer' as indicated in Figure 1. and by the examples which follow. Basically linguistic modelling converts a story or narrative into an organised collection of hypothetical implications or conditionals. 
In accordance with the $1^{\text {st }}$ general principle of systems the structural description of physical, mental and intellectual things is universal supplemented by qualitative and/or quantitative properties or linguistic variables and forms a single domain necessitating a single structure of a linguistic model as shown in Figure 1.

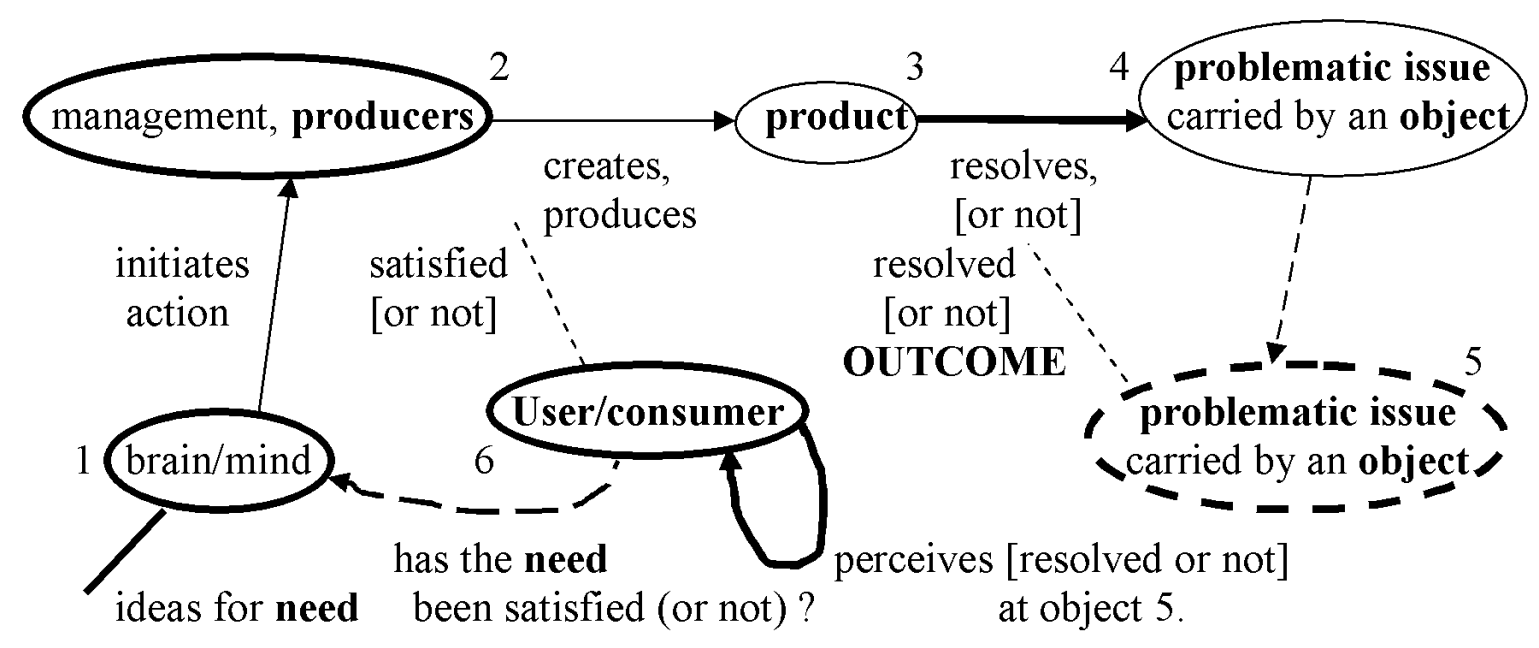

Figure 1. Universal linguistic model of scenarios

Remarks regarding the scheme in Figure 1. :

1. It is based on the 'Cause - Action' scheme [Korn, 2018],

2. It operates in purposive configuration as indicated by the $3^{\text {rd }}$ principle of systems [Korn, 2018] but is applicable to inanimate, natural scenarios governed by 'chance' when 'management, brain/mind' and User/consumer are zero,

3. Its 'outcome' is the resolved, or not, 'problematic issue' perceived by the User/consumer

4. Its 'management, brain/mind' part stands for a person or a group of persons and has envisaged ideas or 'problematic issues' which this part of the scheme wants to see executed to result in 'outcome'. The scheme is an 'idea to outcome converter'.

\section{APPLICATION OF LINGUISTIC MODELLING TO CRISIS SITUATIONS}

\section{Scenario of potential crisis :}

The story is : 'The hotel guest wanted to get to the airport to check in for his flight. He contacted the helpful hotel reception to book the airport bus to collect him who called the spacious airport bus. The bus arrived punctually and took him to the airport where he passed the security to await the announcement for the boarding gate'.

\section{Development of linguistic model which is an instance of the scheme in Figure 1. :}

First, to demonstrate an instance of POINT I.

\section{A. Homogeneous language of context - free, 1 - and 2 - place sentences}

These sentences define the structure or topology or the algorithm of the scenario, they are obtained from linguistic analysis if there are linguistic complexities and needed for constructing semantic diagrams. 
1. Hotel guest contacted hotel reception

2. Hotel reception called the airport bus

3. Airport bus arrived

4. Airport bus took hotel guest

5. Hotel guest passed security

B. Semantic diagram

This is shown in Figure 2.A. to demonstrate the 'structure' of the scenario and constructed initially from the context - free sentences in point $\mathbf{A}$. The semantic diagram acts as an aid to pointing to the qualifiers or 'properties' which are demanded by the symbolism of linguistic modelling [dp, ep etc]. The required qualifiers are obtained from the 'story' or added as demanded by the rules of linguistic modelling and dictated by the subjective judgement of how likely an object is to have a particular property as the logic sequences are developed [Korn, 2009].

C. Adjectival qualifiers with grading and certainty factors (cf) in brackets

Grading can be assigned to qualifiers which, thus, vary and their effect on the performance of the object which they qualify changes. Subjectively assessed certainty factors (cf) can be added to each grade to introduce numerical measures into the emergence of states as a scenario evolves. The technique is explained in detail in [Durkin, 1994, Korn, 2009].

$\mathrm{dp}(1,1)$ - hotel guest wanted to get to.... [has time, .5, urgent, .8]

ep $(1,1)$ - can pay [well, 1]

ip $(1,1)-$ [good communicator, .9]

$\operatorname{ip}(1,7)$ -

ep(2,2) - helpful [very, .7, just, .6]

$\operatorname{ip}(2,3)-$

ep $(4,4)$ - [spacious, 1]

ep $(4,6)-$ [good driver, 1$]$

ip $(4,5)-$

$\operatorname{ip}(4,6)$ -

for the three objects or agents active in the scenario.

D. Interactions with adverbial qualifiers in brackets

in $(1,2)-\mathrm{h} /$ guest contacted $\mathrm{h} /$ reception [to book the a/port bus..... ]

in $(3,4)-\mathrm{h} /$ reception called a/bus

in $(5,5)-\mathrm{a} /$ bus arrived [punctually]

in $(6,1)-\mathrm{a} /$ bus took h/guest [to the airport] which is a 'prompting interaction'

in $(7,7)-\mathrm{h} /$ guest passed [security to await....]

E. Logic sequence/topology of scenario with graded qualifiers and certainty factors

Causal chains from Figure 2.A. : One : 6, 5, 4, 3, 2, 1 and Two : 8, 7, 1 


\section{START}

For One :

1/1. $\mathbf{d p}(\mathbf{1 , 1})[\mathrm{h} / \mathrm{time}, .5$, urgent,.8] $\wedge \mathrm{ip}(1,1)[\mathrm{g} / \mathrm{com}, .9] \rightarrow[.8] \operatorname{in}(1,2)[.4, .64]$

$\mathrm{cf}_{\mathrm{f}}=.8(\min (.5, .9), \min (.8, .9))=.4, .64$

1/2. $\operatorname{in}(1,2)[.4, .64] \wedge \mathrm{ep}(2,2)[$ very,.7,just,.6] $\rightarrow[1] \mathbf{a p}(\mathbf{3 , 3}, \mathbf{3})[.4, .4, .64, .64]$ (h/reception is contacted (to book the...))

$\mathrm{cf}_{\mathrm{f}}=1(\min (.4, .7), \min (.4, .6), \min (.64, .7), \min (.64, .6))=[.4, .4, .64, .64]$

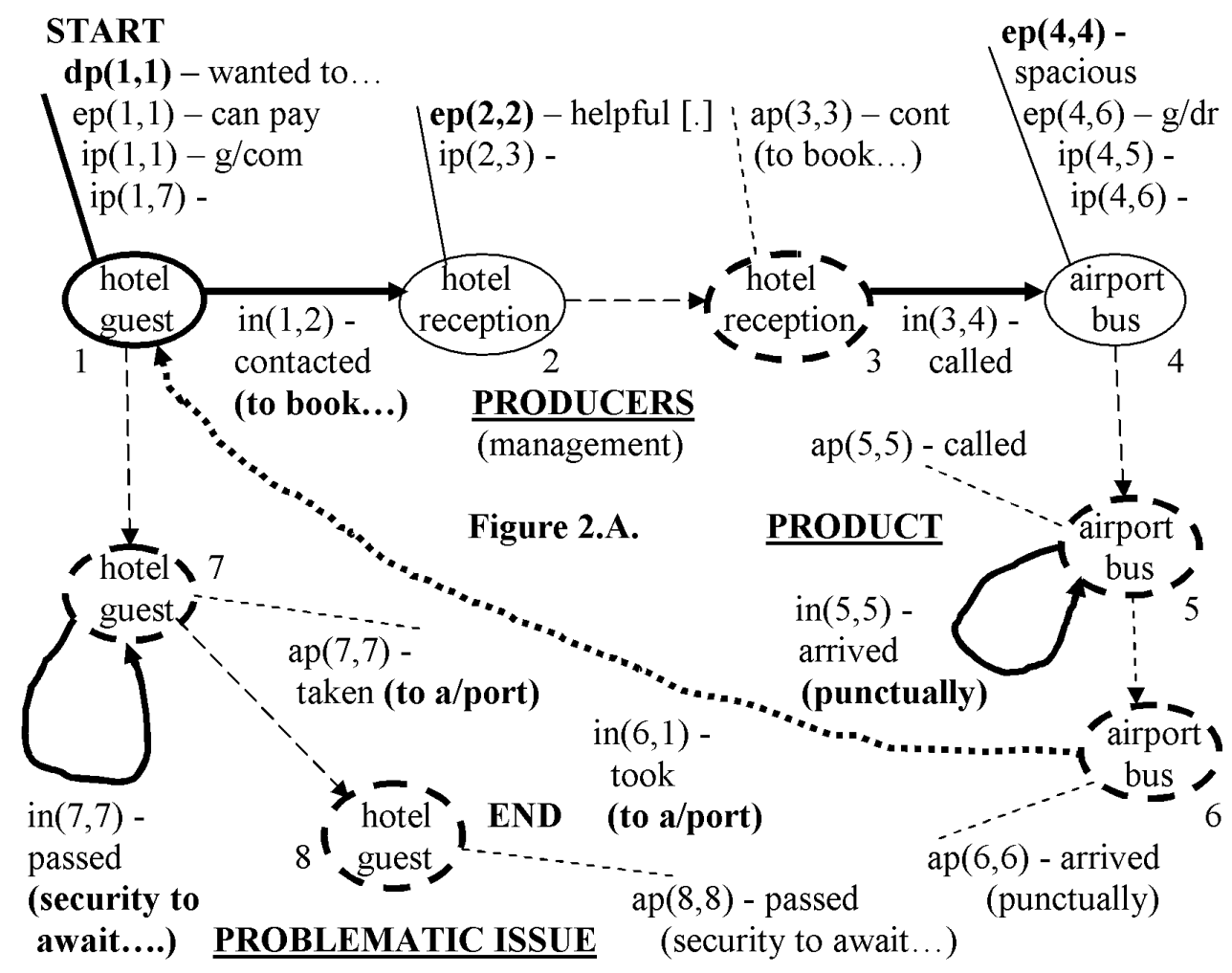

Qualifiers in bold print are obtained from the story of the scenario

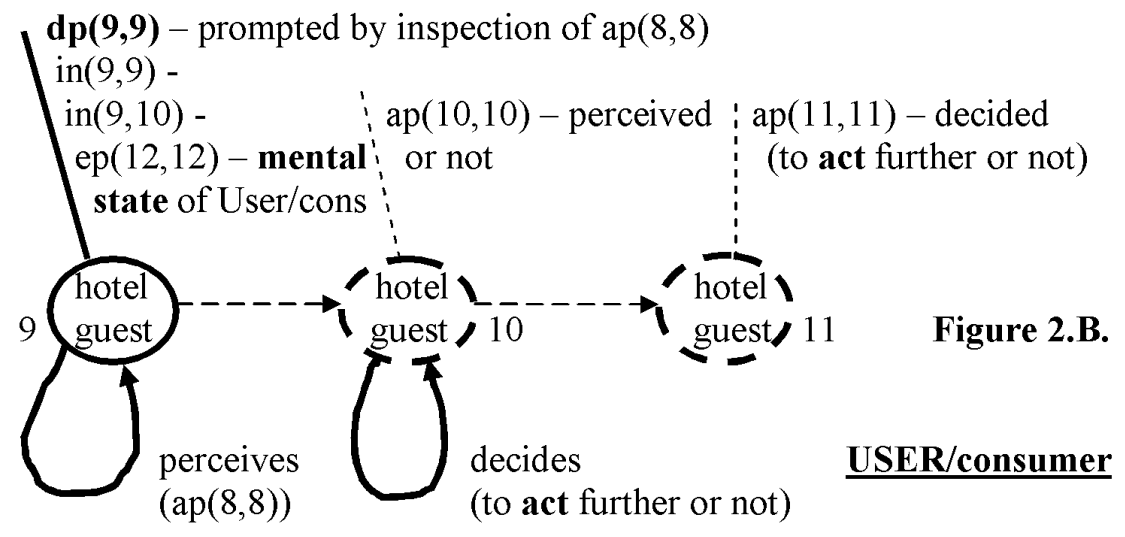

Figure 2. Semantic diagram of 'hotel guest' scenario 
The relations $1 / 1$. and $1 / 2$. initiate different scenarios each with certainty which varies from 'may be (.4) to probably (.64)' with which the ' $\mathrm{h} /$ reception is contacted by the $\mathrm{h} /$ guest (to book...'. The variation is due to the imperfect way each agent is assumed to behave.

$1 / 3 . \quad \operatorname{ap}(3,3) \rightarrow \operatorname{in}(3,4)$

1/4. $\quad \operatorname{in}(3,4) \wedge \mathrm{ep}(4,4) \rightarrow \mathbf{a p}(\mathbf{5 , 5})(\mathrm{a} /$ port bus is called $)$

$1 / 5 . \quad$ ap $(5,5) \rightarrow \operatorname{in}(5,5)$

$1 / 6$. in $(5,5) \rightarrow \mathbf{a p}(\mathbf{6 , 6})(\mathrm{a} /$ port bus arrived (punctually))

1/7. $\quad \operatorname{ap}(6,6) \rightarrow \operatorname{in}(6,1)$

1/8. in $(6,1) \wedge \mathrm{ep}(4,6) \rightarrow \mathbf{a p}(\mathbf{7 , 7})(\mathrm{h} /$ guest is taken (to a/port)) prompting interaction

For Two :

$2 / 1 . \operatorname{ap}(7,7) \rightarrow \operatorname{in}(7,7)$

$2 / 2 . \operatorname{in}(7,7) \wedge \operatorname{ep}(1,1) \rightarrow \underline{\operatorname{ap}(\mathbf{8}, 8)[.4, .4, .64, .64]}(\mathrm{h} /$ guest is passed (security to await...))

END

\section{Remarks :}

The 'problematic issue' carried by the agent 'hotel guest' is ---

Initial State $=$ 'Hotel guest [object 1.] is in the hotel'

Final State = 'Hotel guest [object 8.] is at the airport' which is consistent with IS so the change of state can be achieved by interaction produced by a 'product' which is available from a choice like 'airport bus, taxi, bicycle, walking and so on'. A particular product is selected from appropriate design considerations such as cost, convenience, habit, speed etc based on the requirements primarily generated by the User/consumer by design to match properties of 'product' to its own [Hubka, Eder, 1996].

The 'hotel guest' also plays the part of object or agent initiating action, $\mathrm{h} / \mathrm{she}$ has an objective to achieve which is the 'Final State'. In this example, $\mathrm{h} /$ she also acts as the 'User/consumer' as indicated in Figure 2.B. who observes the state of object 8 . by noting the information in its acquired property, ' $a p(8,8)$ ' [Korn, 2010]. Depending on $\mathrm{h} /$ her interpretation of this, $\mathrm{h} / \mathrm{she}$ takes action as $\mathrm{h} / \mathrm{she}$ sees fit.

There is no more adjectival and adverbial qualifiers with certainty factor less than 1 after relation 1/2. so the certainty factors are transmitted unaltered to the 'outcome' of the scenario at acquired property in relation $2 / 2$. This says that the ' $\mathrm{h} /$ guest passed security with certainty of 'may be (.4)' or 'probably (.64)' [Durkin, 1994].

Figure 2.A. shows in detail the constituents of the universal structure of scenarios in Figure 1. It is a problem solving scheme suggesting a 'design procedure' [considered elsewhere] for constructing prototype systems for resolution of 'problematic issues' to satisfy a 'User/consumer'. The resolution itself, or no resolution, is carried out by the 'product' which is recognised as being the agent which is, through interaction, is necessary and sufficient to change the state of object carrying the 'problematic issue'. 
Figure 2.A. shows explicitly the interpretation of a 'problematic scenario' as a linguistic model in terms of its constituents of objects or agents, their characteristics and qualified interactions as suggested by point I. Accordingly, as an example of 'proactive activity' we look at :

Selected features vulnerable to disaster of 'airport bus' are :

Internal ---

I1. Feature : Runs on rubber tyres

Potential disaster: Puncture of a tyre

I2. Feature : Undetected weak heart of driver

Potential disaster : Heart attack of driver

\section{External ---}

E1. Feature : Airport bus runs along busy streets

Potential disaster : Encountering traffic jams

E2. Feature : Neglected roads due to lack of funds

Potential disaster : Encountering holes in the road surface leading to possible broken suspension

from which the corresponding counter measures or 'new structures' as suggested in point I. are :

MI1. Carrying puncture repair kit

MI2. Monitoring driver's state of health

ME1. Aerial survey of the streets and advise driver

ME2. Borrow money for road repair works.

Selection of features of 'concrete objects' usually presents little difficulty, however, that of living in particular human agents can involve uncertainties and application of disciplines like psychology and knowledge of the workings of the mind. For example, a feature of mental state like 'habitual anger of husband' can result in potential disaster like 'beating wife' the chance of which occurring can be reduced by the countermeasure of 'counselling' before family 'crisis' can take place.

Second, the semantic diagram in Figure 3.A. is developed to demonstrate an instance of POINT II.

From Figure 3.A. we have the causal chains :

One : $10,6,5,4,3,2,1$ and Two: $8,7,1$

\section{START}

For One :

1/1. $\mathbf{d p}(\mathbf{1 , 1})[\mathrm{h} / \mathrm{time}, .5, \mathrm{urgent}, .8] \wedge \mathrm{ip}(1,1)[\mathrm{g} / \mathrm{com}, .9] \rightarrow[.8] \mathrm{in}(1,2)[.4, .64]$

$\mathrm{cf}_{\mathrm{f}}=.8(\min (.5, .9), \min (.8, .9))=.4, .64$

1/2. $\operatorname{in}(1,2)[.4, .64] \wedge \mathrm{ep}(2,2)[$ very,.7,just,.6] $\rightarrow[1] \mathbf{a p}(\mathbf{3 , 3})[.4, .4, .64, .64](\mathrm{h} /$ reception is contacted (to book the...))

$\mathrm{cf}_{\mathrm{f}}=1(\min (.4, .7), \min (.4, .6), \min (.64, .7), \min (.64, .6))=.4, .4, .64, .64$ 
$1 / 3 . \quad \operatorname{ap}(3,3) \rightarrow \operatorname{in}(3,4)$

1/4. in $(3,4) \wedge \mathrm{ep}(4,4) \rightarrow \mathbf{a p}(\mathbf{5 , 5})(\mathrm{a} /$ port bus is called $)$

$1 / 5 . \quad$ ap $(5,5) \rightarrow \operatorname{in}(5,5)$

$1 / 6 . \quad \operatorname{in}(5,5) \rightarrow \mathbf{a p}(\mathbf{6 , 6})[.4, .4, .64, .64](\mathrm{a} /$ port bus is started (on the way))

1/7. $\mathbf{d p}(\mathbf{9 , 9 )}[$ heavy,, .5$] \wedge \mathrm{ap}(6,6)[.4, .4, .64, .64] \rightarrow[1] \operatorname{in}(9,6)[-.5,-.5,-.5,-.5]$

$\mathrm{cf}_{\mathrm{f}}=1(\min (-.5, .4), \min (-.5, .4), \min (-.5, .64), \min (-.5, .64))=-.5,-.5,-.5,-.5$

1/8. $\quad \operatorname{in}(9,6) \rightarrow[1] \operatorname{ap}(\mathbf{1 0}, \mathbf{1 0})[-.5,-.5,-.5,-.5](\mathrm{a} /$ port bus is slowed down $)$

which shows a significant 'slowing down resulting late arrival at the hotel' and possible missing of the plane by the h/guest : a CRISIS situation as far as the ' $\mathrm{h} /$ guest' is concerned. Therefore, a 'calculating property' is introduced as ' $\mathrm{cp}(10,10)[\mathrm{sh} / \mathrm{c}, .9]$ - driver took a shortcut' which is additional evidence representing the initiative of the driver [Korn, 2009].

1/9. $\quad$ ap $(10,10) \rightarrow \operatorname{in}(10,1)$

1/10. in $(10,1)[-.5,-.5,-.5,-.5] \wedge \mathrm{ep}(1,1)[\mathrm{pay}, .8] \times \mathrm{cp}(10,10)[\mathrm{sh} / \mathrm{c}, .9] \rightarrow$

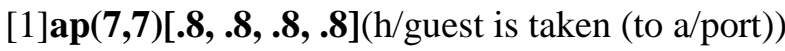

$\mathrm{cf}_{\mathrm{f}}=1(\min (-.5, .8), \min (-.5, .8), \min (-.5, .8), \min (-.5, .8))=[-.5,-.5,-.5,-.5]$

and using the relation for additional evidence from [Durkin, 1994, Korn, 2009]

$\mathrm{cf}_{\mathrm{a}}=\left(\mathrm{cf}_{\mathrm{f}}+\mathrm{cf}_{\mathrm{c}}\right) /\left(1-\min \left(\left[\mathrm{cf}_{\mathrm{f}}\right]\left[\mathrm{cf}_{\mathrm{c}}\right]\right)=(-.5+.9) /(1-\min [.5][.9])=.8, .8, .8, .8\right.$

from which we note the significant improvement in certainty : The ' $\mathrm{h} /$ guest' at object 7 . is 'almost certainly' taken to the 'a/port' which is transmitted to ap $(8,8)$.

For Two :

2/1. ap $(7,7) \rightarrow \operatorname{in}(7,7)$

$2 / 2$. in $(7,7) \rightarrow \underline{\operatorname{ap}(\mathbf{8 , 8})[.8, .8, .8, .8]}(\mathrm{h} /$ guest is 'almost certainly' passed (security to...))

END

Relations $2 / 1$. and $2 / 2$. can be expressed in words :

If the $\mathrm{h} /$ guest is taken (to the a/port) then the h/guest passed (security to await...)

If the $\mathrm{h}$ /guest passed (security to await...) then the h/guest is 'almost certainly (.8)' passed (security to await the announcement for the boarding gate).

\section{Remarks :}


Figure 3.A. shows how crisis situation can arise as far as an individual, the 'hotel guest', is concerned arising from a 'disaster' or a 'disorder' unexpected as far as the 'airport bus' is concerned and has materialised out of the normal course of events as suggested in point I. However, the 'driver of the airport bus' playing the part of 'crisis management' took the initiative and averted the crisis by 'taking a short cut'. In this case, th effect of 'crisis management' is taken into account by introducing a 'calculating property, 'cd', which is a device in linguistic modelling.

The 'traffic jam' which plays the part of 'disorder', appears unexpected to the 'driver of the airport bus' but, in general, events can evolve gradually before they are perceived as 'disasters' or 'disorders'. For example, in the 'health service' of a country doctors can gradually resign due to better pay and working conditions elsewhere before the 'health service' is declared to be in a 'crisis situation' because it is seen to be unable to provide the services to patients as expected in normal circumstances and as such the situation is 'life threatening'. Also, 'disasters' do not necessarily followed by 'crisis situations'. For example, 'collapse of the bridge across a river last month' was an unexpected, instantaneous and local event which was not followed by a situation considered to be a 'crisis'. In the case depicted in Figure 3.A. the effect of 'delay by the airport bus' need not have been a 'crisis situation' if the 'hotel guest' could have caught a later aeroplane.

\section{DISCUSSION}

The structural nature of any part of the world is universal which is asserted by the $1^{\text {st }}$ general principle of systems. Accordingly, the structural or systemic description is pervasive, empirical and indivisible and supplemented by the application of a particular

selection of qualitative and/or quantitative properties dependent on the view, taste or opinion of an observer. Systemic description of 'aggregates' of constituents in static or

dynamic state shows the existence of outcomes which is indicated in Figure 1. in case of human activity scenarios which is the general case [Korn, 2018].

The term 'outcome' refers to attempting resolution of a 'problematic issue' by a 'product' through its interaction so as to induce the change from 'initial to final state' of object carrying the 'problematic issue' as shown in Figure 2.A., for example. The change of state is carried out so as to match the expectation of a User/consumer shown in Figure 2.B. if there is one. The term 'problematic issue' designates a statement of 'initial state' of affairs carried by a theoretical object which is subjectively regarded as 'problematic' and is based on an impression to lead to a consistent final state which is supposed to be its resolution. A 'theoretical object' is a part of the world concrete, abstract or symbolic which is predicated by one or more statements such as object 1. in Figure 3.A., for example. An 'empirical object' is one that is perceived by any of the senses as a whole. We have the following cases or kinds of outcomes of scenarios :

1. Activities by aggregates composed of : Inanimate, natural objects like a 'volcano' which are directed at achieving a state of equilibrium, 'static' like a 'rock embedded in the side of a mountain' or 'dynamic' like the 'steady flow of a river'.

Achievement of a state of equilibrium is the objective of all activities otherwise there would be chaotic, incessant changes prevailing at all times in all places. In this case the outcome of an aggregate is seen as the state of static or dynamic equilibrium preceded by generation of heat due to 'losses' such as friction, as described by the $2^{\text {nd }}$ law of thermodynamics [Korn, 2012]. 

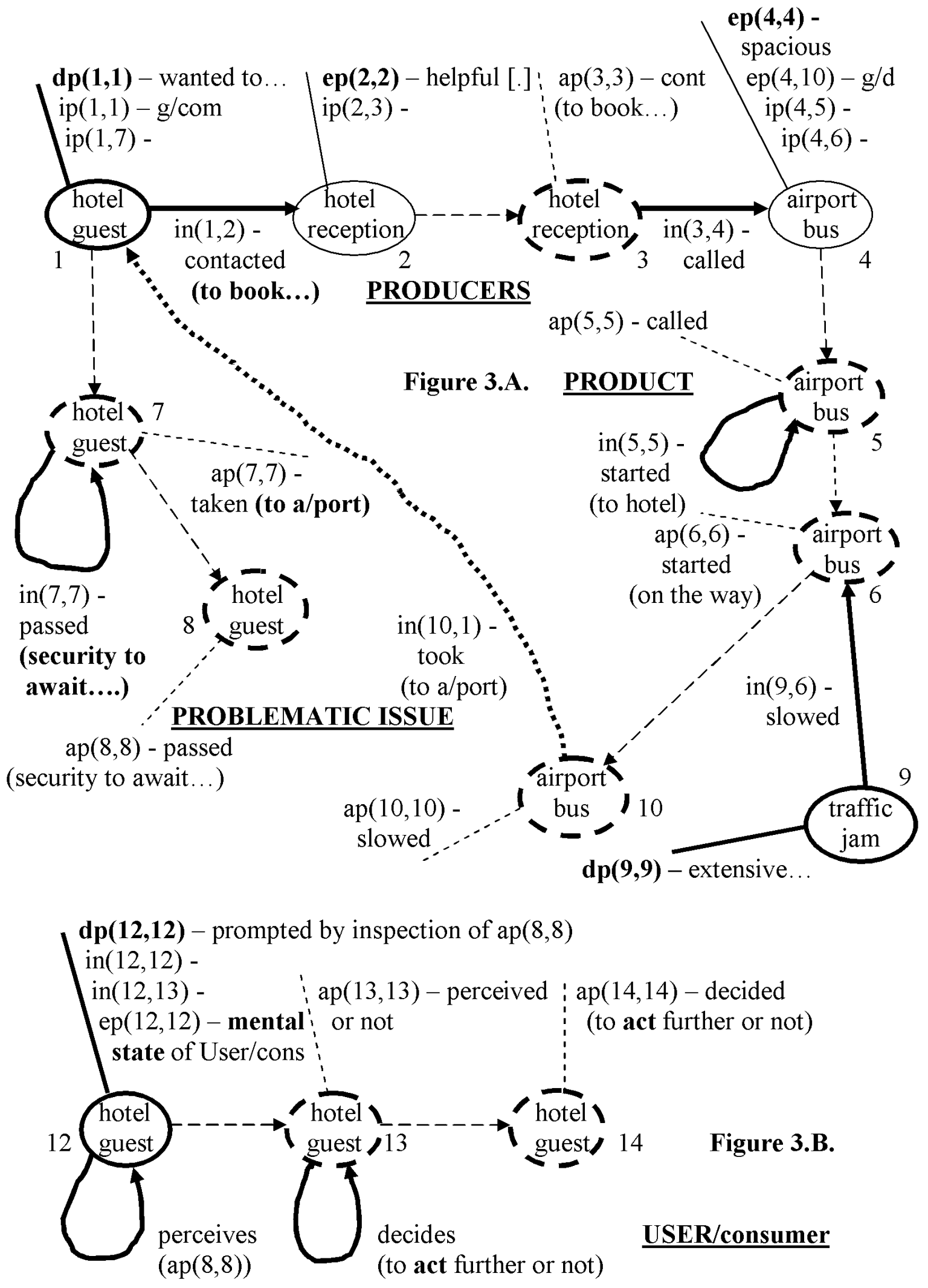

Figure 3. Semantic diagram of modified 'hotel guest' scenario 
2. Activities by aggregates composed of : Inanimate, artificial objects like an 'engineering, control system' or a robot which are directed at achieving a final state of a 'problematic issue' set by a human element. This state is the equilibrium state of an aggregate which can be static [position control] or dynamic [speed control] which is its outcome as indicated in Figure 1. [Nise, 2008, Korn, 2012].

3. Activities by aggregates composed of : Wholly or partly by human beings like a 'church congregation' or a 'train accelerating towards a station' which are directed at achieving a final state of a 'problematic issue' set by a human element. The rest is the same as in point $\mathbf{2}$. except the final states the range of which, apart from survival, is infinite because the ideas for action and inventions generated by human imagination is infinite. They can be directed towards achievement of ambitions, creating 'products' for convenience, entertainment, reaching to new places, creating new expressions as in art and so on with human constituents requiring special physical environments. The problematic situations with crisis belongs to this category.

Final states to be achieved by plants and animals are set by the hereditary mechanism and restricted to serve survival. The scheme in Figure 1. is still applicable with 'producers' with 'management' provided by a brain/mind assembly directed by instinct fuelled by the hereditary mechanism and chance, 'product' such as grazing, 'problematic issue' such as hunger and User/consumer which is the plant or animal itself. No artificial products are produced.

\section{Activities by aggregates composed of :}

1. Humans, inanimate, artificial objects, or

2. Animals and/or plants and inanimate, natural objects engaged in activities in ---

Manufacturing [fabricating components of car engines, bird carrying twigs], assembling [assembling car engines or a nest of twigs], delivery [transporting cars to dealers or food to young] or service systems [preparing hotel room for a guest]. They deal with creating products to be represented as 'linguistic networks' which yield a variety of choices through variation of their topology and act as a numerical measure of complexity [Korn, 2009, 2013].

Categories 1., 2., 3. are called 'consumer systems', 4. is called 'production systems'. In categories 2., 3., 4. aggregates or systems are engaged in problem solving because 'problematic issues' can be identified and their resolution requires structures operating in purposive configuration which must be designed or 'engineered' [Lewin, 1981].

The model for implementing the 'principles of structural description' pervading the contents of points 1., 2., 3., 4. needs to be universal, a characteristic possessed by the symbolism of processed natural language supplemented by 'mathematical models of conventional science' at the individual or object level to aid decision making or computation, for example. The semantic diagram in Figure 2. depicts such a model [Korn, 2018]. This is done essentially by linguistic modelling which formalises a story or narrative in 'natural language' with or without making a 'problematic issue' explicit.

Points I., II. have been arrived at from consideration of the topics currently available in the field of studies of crisis situations. This is followed by the application of 'systems thinking' in particular 'linguistic modelling' demonstrated by a simple example. Based on the discussion above, crisis situations fit into category 3 . with all categories covering the spectrum of possibility of occurrence of outcomes. 


\section{Linguistic modelling is characterised by ---}

1. 'For a given whole represented by a semantic diagram of 'management/producers and product' the outcome or resolution of a 'problematic issue' necessarily follows, subject to :

Resolution is acceptable to User/consumer,

All theoretical objects exist and behave i.e. interact as prompted by their individual characteristics. For example, an elastic spring when 'compressed as a result of stored mechanical energy' and 'released', will produce an 'interaction of force' or a person when 'benevolent' and 'encounters a beggar', is likely to produce an 'interaction by giving money'. This notion integrates divers phenomena from different domains. However, the difference is that in the first case the interaction prompted or triggered is determined but in the second it is only probable.,

Progression of correct semantic correctness. For example, 'a person furious with his neighbour smiles at $\mathrm{h} /$ her at the same time' describes a physically impossible event which blocks progression',

Acceptable uncertainty,

Correct matching of properties of constituents of producers and product to User/consumer.

2. A symbolism usually is created to say something about a part of the world, it carries information [Korn, 2010]. Since any part of the world is structurally organised according to the $1^{\text {st }}$ principle of systems to carry out its task a symbolism must also be structurally organised, it is a 'system'. A major problem with all kinds of symbolisms used for creating models of parts of the world is their relation with these parts or the establishment of meaning of elements of a symbolism. In conventional science of physics the meaning of quantifiable symbols is precisely and operationally determined to be fed into mathematical models [Anon.,1970]. In the Viable Systems Model of S. Beer, for example, the meaning of symbols is vague or not stated [Jackson, 2000]. In other fields such as astrology the relation between a symbol such as 'movement of the planet Mars in a certain way' and the 'predicted events concerning a certain type of person' is not established.

The symbolism of linguistic modelling is elements of natural language organised into reasoning schemes and the relation or meaning of these elements to parts of the world is well established.

3. The availability of explicit, structural description facilitates consideration of any number of alternative structures and/or agents or objects with different characteristics for the achievement of resolution a 'problematic issue' acceptable to a User/consumer.

The three principles of systems with linguistic modelling as the symbolism of their means of implementation and including application of conventional science of physics, is suggested to create an integrated scientific enterprise [Korn, 2018]. It has its roots in branches of knowledge, eminently teachable and gives guidance to problem solving through design thinking. However, it has not been applied to larger scale scenarios like parts of an organisation or world problems [Meadows, et al., 1972] and needs software development to work out the dynamics of scenarios designated by the dotted, directed lines in Figure 2., selection from alternatives and possibly learn from the exercise etc. A possible connection with AI may need to be explored.

\section{RÉFÉRENCES}

Anon., (1994). Chambers Dictionary. Chambers Harrap Pub Ltd., Edinburgh, UK.

Anon., (1970). The International System of Units. HMSO, London, UK.

Burton, S. H. (1984). Mastering English grammar. Macmillan, London, UK. 
Coombs, W. T. (1998). "An analytical framework for crisis situations. Better responses from a better understanding of the situation". J of Public Relations Research, v10, n3:177-192.

Durkin, J. (1994). Expert systems. Macmillan, NY, USA.

Gilpin, D. R., Murphy, P. J. (2008). Crisis management in a complex world. Oxford U P, Oxford, UK.

Hubka, V. Eder, W. E. (1996). Design science. Springer, London, UK.

Jackson, M. C. (2000). Systems approaches to management. Plenum Pub., NY, USA.

Jaques, A. (2010). "Reshaping crisis management: the challenge for organizational design". Organizational Development J, v28, n1:9-17.

Khodarahmi, E. (2009). "Crisis management, Disaster Prevention and Management". v18, n5:523528.

Korn, J., Huss, F. Cumbers, J. (1991). "Construction of causal networks through linguistic modelling”. AI in Simulation, IEE Colloquium, 29 April, London, UK:11-23.

Korn, J. (2009). Science and design of systems. Troubadour Publishing, Leicester, UK.

Korn, J. (2010). "Concept and design of information and IS". UKAIS Conf, 24/25 March, Oxford, UK: 97-116.

Korn, J. (2012). Network modelling of engineering systems. Troubadour Publishing, Leicester, UK.

Korn, J. (2013). Linguistic modelling of scenarios. Troubadour Publishing, Leicester, UK.

Korn, J. (2015). "Paradigm change from the systemic view to systems science". International J. of Systems and Society, v2, n1:44-64.

Korn, J. (2016). The purpose of change is problem solving. Troubadour Publishing, Leicester, UK.

Korn, J. (2018). "General principles of systems". Kybernetes, https://doi.org/10.1108/

K-09-2017-0348.

Kuhn, Th. (1996). The structure of scientific revolutions. U of Chicago, PA, USA.

Lewin, D. (1981). "Engineering philosophy. The third culture". Proceedings of the $J$ of the Royal Society of Arts, v129, n5302:653-666.

Meadows, D. H., Meadows, D. L., Randers, J., Behrens, W. W. (1972). The limits of growth : A report for the Club of Rome's project on the predicament of mankind. Universal Books, NY, USA.

Nise, N. S. (2008). Control systems engineering. Wiley, Chichester, UK.

Wang, C. T., Wang, H. L., Chen, Y. C. K. (2018). "A study of crisis response strategies for crisis handling, International". J of crisis management, v8:41-49. 